\title{
Pressões institucionais na divulgação ambiental das empresas do BRICS
}

\section{Institutional pressures on environmental disclosure by companies in BRICS}

\author{
SANDRA MICHELINNE SARAIVA DE SOUSA AMORIM* \\ MARCELLE COLARES OLIVEIRA** \\ VERA MARIA RODRIGUES PONTE*** \\ MÔNICA CAVALCANTI SÁ DE ABREU $U^{* * * *}$
}

\section{RESUMO}

O estudo propõe-se a identificar a influência do ambiente institucional dos países do BRICS no nível de divulgação de informações ambientais pelas suas empresas do setor de energia elétrica. Foi utilizada análise de conteúdo para analisar os relatórios anuais e de sustentabilidade de 90 corporações do BRICS e foi usada ANOVA, t-test, Kruskal-Wallis test, Tukey's post-hoc test e árvore de regressão para examinar e comparar o nível de divulgação de acordo com a Teoria Institucional. Concluiu-se que aquelas com mais alto nível de divulgação fazem parte de índices de sustentabilidade. Esse resultado ressalta a influência das pressões culturais. As empresas que apresentaram mais baixo nível de divulgação foram aquelas cujos sistemas legais de seus países são codificados ou mistos e não fazem parte de índices de sustentabilidade. As empresas brasileiras e russas apresentaram maior nível de divulgação que chinesas e indianas estudadas. Esses achados reforçam a relevância de instituições como bolsas de valores e índices de sustentabilidade na divulgação ambiental,

* Professora Assistente I da Universidade Federal do Piauí, Brasil, Mestre em Administração e Controladoria pela Universidade Federal do Ceará, sandramichelinne@gmail.com .

** Professora Associada IV da Universidade Federal do Ceará, Brasil, Dra. em Ciências Contábeis pela Universidade de São Paulo, marcellecolares@uol.com.br .

*** Professora Associada I da Universidade Federal do Ceará, Brasil, Dra. em Ciências Contábeis pela Universidade de São Paulo, vponte@fortalnet.com.br .

**** Professora Associada III da Universidade Federal do Ceará, Brasil, Dra. em Engenharia da Produção pela Universidade Federal de Santa Catarina, mabreu@ufc.br . 
tendo mais influência que exigências legais (pressões coercitivas) e que as verificações externas dos relatórios de sustentabilidade, realizadas por instituições como a GRI e as empresas de auditoria, associadas a pressões normativas.

Palavras-chave: Responsabilidade Social Corporativa; divulgação ambiental; Teoria Institucional; BRICS.

\section{Abstract}

The research aims to identify the influence of institutional environment of BRICS countries on level of environmental information disclosure of local electricity companies. It was used content analysis to analyze data from the annual and sustainability reports of 90 companies of BRICS countries from electricity sector and used ANOVA, t-test, Kruskal-Wallis test, Tukey's post-hoc test and regression tree to analyze and compare the level of disclosure of the companies according to the Institutional Theory. It was concluded that companies with the highest level of disclosure are part of sustainability indexes. This result highlights the influence of cultural pressures. Companies that present the lowest level of disclosure are those that their countries are based in common law or mixed legal system and they are not part of any sustainability indexes. Brazilian and Russian companies presented a higher level of environmental disclosure than Chinese and Indian studied. These findings highlights the importance of the role that institutions such as stock exchanges and their sustainability indexes play on influencing the disclosure of environmental information, having a bigger influence on disclosure than legal requirements (coercive pressures) and external verification of sustainability reports (normative pressures) by GRI and auditing firms.

Keywords: Corporate Social Responsibility; environmental disclosure; Institutional Theory, BRICS.

\section{INTRODUÇÃO}

A preocupação com a postura socioambiental das empresas nos anos de 1990 fez com que o conceito de investimentos socialmente responsáveis ganhasse corpo. Pesquisadores afirmam que o desenvolvimento dos índices de sustentabilidade ligados aos mercados de capitais possibilita aos stakeholders uma visão mais aprofundada 
a respeito do desempenho corporativo da sustentabilidade e que empresas participantes desses índices seriam mais social e ambientalmente ativas (ZIEGLER; SCHRÖDER, 2010).

A publicação de informações socioambientais não é obrigatória na maioria dos países, embora tenha se tornado uma prática cada vez mais constante pelas empresas. Entre as formas de divulgação estão os relatórios socioambientais, também conhecidos como relatórios de sustentabilidade ou balanços sociais, divulgados em seus sites ou em meio impresso, bem como disponibilizados por instituições, como bolsas de valores, comissões de valores mobiliários ou outras instituições assemelhadas ou não a essas.

Alguns setores considerados mais poluidores sofrem mais pressão para divulgar essas informações, entre os quais destaca-se o de energia elétrica, por ser considerado um dos que mais provoca impactos ambientais (MOSEÑE et al., 2013; SILVEIRA; PFITSCHER, 2013; BRAGA; SILVA; SANTOS, 2015; BEUREN; SANTOS; GUBIANI, 2013; MORISUE; RIBEIRO; PENTEADO, 2012).

Estudiosos afirmam que as empresas de setores ambientalmente sensíveis, como o de eletricidade, são mais propensas a publicar esse tipo de informação como resultado da grande pressão pública ou ainda por comporem carteiras de índices de sustentabilidade (CARNEIRO; DE LUCA; OLIVEIRA, 2008; SOUZA; RÁSIA; JACQUES, 2010; GUBIANI; SANTOS; BEUREN, 2012; RODRIGUES; SALLABERRY, 2012).

Fundamentadas na não obrigatoriedade de evidenciação das informações ambientais, pesquisas foram realizadas para identificar os fatores que levam as empresas a adotarem tal prática, justificando os achados com base nas teorias organizacionais, como a Teoria da Divulgação Voluntária, a Teoria dos Stakeholders, a Teoria da Divulgação, a Teoria do Disclosure Discricionário e a Teoria Institucional (BEWLEY; LI, 2000; LIU; AMBUMOZHI, 2009; BRAGA; OLIVEIRA; SALOTTI, 2009; ZENG et al., 2012; OLIVEIRA; ARAÚJO JÚNIOR; OLIVEIRA; PONTE, 2012; OLIVEIRA; PONTE JUNIOR; OLIVEIRA, 2013; DIAS FILHO; MOURA, 2013).

Considerando-se que as ações adotadas variam entre si e decorrem de motivos distintos, como imposições legais, normativas ou sociais, a Teoria Institucional, a fim de permear essa diversidade, 
tem sido gradativamente aplicada em vários estudos (ROLDAN et al., 2012; ZENG et al., 2012; OLIVEIRA et al., 2013; ABREU; CUNHA; BARLOW, 2015). Essa teoria oferece múltiplas percepções relativas ao exame das pressões institucionais em contextos diversos e das consequentes atitudes organizacionais, as quais tendem a assemelhar-se, no caso de entidades expostas, a conjunturas similares, remetendo-se ao isomorfismo institucional (DIMAGGIO; POWELL, 1983).

Nesse contexto de postura socioambiental responsável e de desenvolvimento sustentável, alguns dos maiores mercados emergentes uniram seus esforços a partir dos anos 2000 e em 2012. Os líderes de Brasil, Rússia, Índia, China e África do Sul (BRICS) reuniram-se na Índia para liderar o quarto encontro que tratou de assuntos como comércio, economia global, agricultura, saúde e inovação, terrorismo internacional, mudanças climáticas, comida e segurança energética.

Embora sejam muitos os estudos que investigam o nível de difusvulgação de informações ambientais - como sua associação com a participação das empresas que divulgam em índices de sustentabilidade, bem como com a voluntariedade versus a obrigatoriedade dessa postura -, existe ainda a lacuna no tocante a uma abordagem apoiada na análise teórica dos achados (SEHNEM; SANTOS JUNIOR; DIAS, 2013). Ainda que existam vários estudos que comparam a divulgação socioambiental das empresas em vários países, não há muitas pesquisas que abordam o BRICS - especialmente considerando apenas o setor elétrico -, apesar da sua relevância na economia mundial (DE VILLIERS; ALEXANDER, 2010).

Este estudo, propõe-se a investigar o seguinte problema: qual a influência do ambiente institucional dos países do BRICS no nível de divulgação de informações ambientais pelas empresas do setor de energia elétrica? Desse modo, o objetivo da pesquisa é identificar a influência das pressões do ambiente institucional dos países do BRICS no nível de divulgação de informações ambientais.

A realização deste trabalho se justifica por contribuir para a discussão sobre as explicações para o nível de divulgação ambiental à luz da Teoria Institucional. A pesquisa é relevante também pela carência de estudos com essa ênfase específica, já que houve outros que compararam países acerca da adoção e divulgação de 
práticas socioambientais (LATTEMANN et al., 2009; DE VILLIERS; ALEXANDER, 2010).

\section{REFERENCIAL TEÓRICo}

\subsection{Isomorfismo institucional e divulgação ambiental}

Segundo Cunha, Soares e Lima (2011), as organizações se apresentam à sociedade de forma cada vez mais homogênea na medida em que suas estratégias de gestão são intensificadas, passando a ser vistas como estratégias de diferenciação e, portanto, utilizadas por todas do mercado. Tal prática consiste num benchmarking em que o objetivo é a comparação com os concorrentes na busca pela obtenção de uma eficiência mais elevada em prol de uma evolução contínua, resultando na prática do isomorfismo.

Para Meyer e Rowan (1977), a ideia central do isomorfismo institucional está na conformidade das corporações com mitos racionalizados na sociedade sobre o que constitui uma organização ideal. Corroborando essa afirmação, para Oliveira et al. (2012, p. 5), "o isomorfismo ocorre quando uma organização adota os procedimentos e práticas já desenvolvidos e aprovados em outras organizações pertencentes ao mesmo ambiente".

Conforme DiMaggio e Powell (1983, p. 147), "uma vez que um conjunto de organizações emerge como um campo, um paradoxo que surge é: atores racionais tornam suas organizações mais semelhantes à medida que eles tentam mudá-las". Tal resultado é atingido por meio de três processos de isomorfismo: coercitivo, mimético e normativo.

O mecanismo coercitivo ocorre por meio das pressões formais (exercidas sobre a organização por outras às quais elas são dependentes) e informais (exercidas por expectativas culturais da sociedade, na qual as companhias funcionam). Assim, tais pressões podem ser sentidas como força, persuasão ou como convites para participar em conluio (DIMAGGIO; POWELL, 1983). Os instrumentos representativos desse tipo de mecanismo são regras, leis e sanções.

O isomorfismo mimético resulta da padronização de respostas à incerteza, que consiste numa poderosa força que incentiva a imitação. As organizações assumem postura de mecanismo mimético 
diante da má compreensão de tecnologias, metas ambíguas ou quando o ambiente cria incerteza simbólica. Dessa forma, modelam-se a outras organizações similares em seu campo percebidas como mais legítimas ou bem-sucedidas (DIMAGGIO; POWELL, 1983).

Para Jensen e Berg (2012), os processos miméticos implicam que os gestores copiam estratégias de organizações bem-sucedidas (ou concorrentes) que são consideradas como melhores práticas. Segundo Cunha, Soares e Lima (2011, p. 10), “outras organizações servem de exemplo para que a gestão possa ser modelada". Assim, crenças comuns, lógica compartilhada de ação e isomorfismo constituem os instrumentos desse mecanismo.

Para esse tipo de mecanismo, toma-se como exemplo a imitação dos concorrentes pela indústria com relação à adoção de estratégias ambientais com o intuito de não perderem clientes e credibilidade; a participação das empresas nos índices de sustentabilidade criados pelas bolsas de valores para refletir o retorno de uma carteira composta por ações de empresas comprometidas com a responsabilidade social e a sustentabilidade empresarial, promovendo e incentivando as boas práticas no meio empresarial; e a representação de gestores de organizações altamente visíveis nos conselhos de outras organizações, como forma de terem sua estrutura reforçada.

Já o isomorfismo normativo decorre principalmente da profissionalização, interpretada por DiMaggio e Powell (1983) como uma luta coletiva dos membros de uma organização a fim de definir as condições e os métodos de seu trabalho para controlar a produção de procedimentos e para estabelecer a base e legitimação de sua autonomia ocupacional. Os instrumentos que conduzem a esse tipo de mecanismo são a certificação e acreditação.

Luz e Rossoni (2012) lecionaram que a frequente associação das pressões normativas às profissões justifica-se pela internalização de valores nos profissionais, que é decorrente da educação semelhante que recebem, o que proporciona a definição daquilo que é moralmente aceito. Desse modo, como possuem valores em comum, a tendência é que favoreçam a adoção de práticas socialmente validadas e semelhantes àquelas incorporadas na profissão. 
Oliveira et al. (2013) ressaltaram que a força que cada um desses mecanismos terá no contexto da institucionalização dependerá do contexto local e do tipo de sociedade. Como exemplo disso apontaram a observação frequente do isomorfismo normativo em contextos com alto nível de competição; do coercitivo em contextos cujo regime é patrimonialista, autoritário e controlado pelo governo; e do mimético em contextos em que as organizações adotam práticas e processos de organizações de sucessos pertencentes ao mesmo ambiente.

De acordo com a Teoria Institucional, é possível afirmar que a decisão de divulgar informações sociais e ambientais, bem como o nível dessa divulgação, vai além do atendimento às pressões das partes interessadas; ela abrange fatores relacionados ao ambiente institucional enfrentado pelas empresas que exerce forças isomórficas sobre a divulgação das empresas (NORTH, 1991; MEYER; ROWAN, 1977; DIMAGGIO; POWELL, 1983; DE VILLIERS; ALEXANDER, 2010).

Segundo Hossain e Hammami (2009), a divulgação voluntária nos relatórios anuais depende da motivação gerencial, da cultura, do sistema jurídico e do enquadramento institucional do país no qual as empresas atuam.

A relevância de práticas sustentáveis e de Responsabilidade Social Corporativa (RSC) cresceu em virtude do impacto das atividades empresariais no ambiente e na sociedade, o que levou as empresas a divulgarem suas práticas, principalmente devido às pressões crescentes de agentes diversificados. No entanto, podem existir diferenças nas atividades corporativas e na divulgação entre os países, algo proveniente das diferentes realidades sociais e expectativas (GRECCO et al., 2013).

Apesar de a divulgação de informações ambientais não ser de caráter obrigatório, segundo Broberg, Tagesson e Collin (2010), a opção das empresas por tornar públicas voluntariamente informações adicionais, que geralmente abrangem dados financeiros, estratégicos, ambientais e sociais, entre outras naturezas, tem como finalidade satisfazer às demandas do mercado de capitais. No entanto, ressaltam que há variação quanto à extensão e ao conteúdo das informações constantes nessas divulgações voluntárias, o que pode ser explicado por fatores oriundos da Teoria Institucional, bem como por pressões internacionais do mercado de capitais. 


\subsection{Divulgação ambiental e aspectos do ambiente institucio- nal dos países do BRICS}

Criado em 2001 e inicialmente concebido como o acrônimo BRIC, abarcou as quatro maiores economias emergentes no mundo (Brasil, Rússia, Índia e China) e permaneceu por vários anos como uma ferramenta de análise prospectiva da economia mundial até adquirir um significado político em 2008. Em 2010, a África do Sul passou a integrar o grupo, o que fez com que fosse acrescentada a letra "S" (South Africa) à sigla BRIC, formando assim o BRICS. $\mathrm{O}$ aumento do impacto negativo sobre o meio ambiente por parte desses países tem levado a uma preocupação crescente com relação às políticas ambientais e à existência de alguns interesses comuns nessa área. Entre os principais impactos estão as emissões de gases causadores de efeito estufa (GEE), a degradação do solo resultante do agronegócio e a perda da diversidade biológica. A fim de mitigar os impactos negativos da poluição atmosférica, esses países vêm lançando programas e planos nacionais sobre eficiência energética e mudanças climáticas (MIKHAILOVA, 2011).

Destaca-se também a criação de índices de sustentabilidade que fazem parte das bolsas de valores desses países, cuja inclusão de empresas neles pode ser vista como um indicador de desempenho para a sustentabilidade corporativa (ZIEGLER; SCHRÖDER, 2010). A elaboração desses índices, conforme informações contidas nos sítios das bolsas de valores, teve como finalidade a sustentabilidade. Além disso, a preocupação com o meio ambiente é demonstrada numa série de regulamentações expressas sobre o tema, a fim de promover sua preservação, bem como orientar sobre a divulgação das ações implementadas para que essa proteção aconteça.

A expectativa maior sobre a qualidade e a quantidade de informação ambiental divulgada ocorre sobre as empresas pertencentes a índices de sustentabilidade, pois são consideradas mais socialmente responsáveis (ROVER et al., 2012). Por isso, entre os critérios de seleção das bolsas de valores do BRICS para que as empresas componham as carteiras desses índices está a observação de atendimento aos princípios do Triple Bottom Line, o qual envolve a avaliação de elementos ambientais, sociais e econômico-financeiros. Portanto, os 
relatórios de sustentabilidade tornam-se importantes ferramentas para a evidenciação dessa informação.

Assim como a divulgação de informações ambientais e relatórios de sustentabilidade são voluntários na maioria dos países, sua verificação externa ou auditoria também são voluntários; no bloco do BRICS também não há exigibilidade para sua elaboração, publicação e verificação. Entretanto, em muitos países, com vistas a dar maior credibilidade a essa informação, empresas de auditoria e outras organizações realizam sua verificação, e padrões foram estabelecidos para ser usados com esse propósito, visando a maior uniformidade. O trabalho de asseguração externa é realizado com base em diferentes normas internacionais, como a Global Reporting Initiative (GRI) (2011), a AA1000 Assurance Standard e a norma International Standard on Assurance Engagements (ISAE) 3000. A AA1000 Assurance Standard possibilita às entidades responsáveis pela verificação um controle de dados essencial para avaliar a forma pela qual as organizações relatoras desenvolvem a gestão da sustentabilidade (GOMES, 2012).

A extensão da regulamentação jurídica de um país sofre grande impacto dos sistemas jurídicos, que podem ser distinguidos entre direito comum (Common Law) e direito civil ou codificado (Code Law). Como as empresas se encontram fortemente enraizadas dentro do sistema jurídico do país de origem, supõe-se que adotem as principais características desse sistema jurídico (JENSEN; BERG, 2012).

O sistema jurídico dos países do BRICS apresenta características diferentes. No Brasil, ele segue a tradição do direito civil; na Rússia, com o processo de democratização, houve a mudança da lei soviética ao direito civil; na Índia, é amplamente baseado no direito comum inglês e notavelmente pluralista; na China, é uma mistura complexa de abordagens tradicionais chinesas e influências ocidentais (RAMANUJAM et al., 2012); e na África do Sul também é baseado no direito comum (RAUTENBACH, 2008). Essa classificação é importante para entender as práticas de divulgação ambiental nesses países, que podem ter no sistema jurídico uma das explicações para o nível ser baixo ou elevado. 


\subsection{Hipóteses}

Considerando os aspectos do ambiente institucional, é proposta a seguinte hipótese geral (HG): o nível de disclosure de informações ambientais apresentado pelas empresas do setor de energia elétrica dos países do BRICS diverge devido ao sistema jurídico do país, à inclusão em índices de sustentabilidade e à verificação dos relatórios anuais e/ou socioambientais.

\subsubsection{Sistema jurídico}

Jensen e Berg (2012) assinalam que os relatórios anuais das companhias são importantes ferramentas para assegurar transparência, uma vez que são focados em amplo grupo de stakeholders, não somente nos acionistas; assim, é esperada a divulgação de alguns aspectos relevantes para a sociedade, incluindo questões sociais e ambientais.

Estudos recentes mostram que a despeito da existência de leis regulando as práticas e divulgação das empresas buscando a proteção de seus vários stakeholders, incluindo investidores e muitos outros, em países emergentes, o que inclui os países do BRICS, o maior problema é ainda a efetividade na conformidade com as leis, conhecida na literatura internacional como enforcement (BLACK; CARVALHO; GORGA, 2010; CHENNUPATI; POTLURI; MAGNALE, 2013; DHARMAPALA; KHANA, 2013; ESTRIN; PREVEZER, 2011; JIA et al., 2009).

A divulgação de informações ambientais é considerada como voluntária, pois está embasada apenas em diretrizes e recomendações (ROVER et al., 2012). O disclosure voluntário, segundo Murcia et al. (2008), envolve informações que não são obrigatórias por lei, mas que proporcionam maior transparência para a empresa no âmbito corporativo.

Lattemann et al. (2009) lecionaram que a não obrigatoriedade da divulgação de informações ambientais faz com que haja desconfiança por parte do público que, em contraste, deposita mais confiança na comunicação corporativa das sociedades baseadas em regras.

Dessa forma, o nível de divulgação pode estar associado ao sistema jurídico dos países aos quais as empresas pertencem. Conforme Botinha, Pontes e Rech (2013, p. 98), “o sistema jurídico de 
um país tem sido utilizado para justificar as diferenças na qualidade das informações contábeis e seu processo de produção e elaboração de normas contábeis".

Nos países de sistema jurídico Code Law, a contabilidade se desenvolve baseada em leis, ao passo que nos de Common Law é realizada de maneira diferente, já que, segundo Botinha, Pontes e Rech (2013), esse sistema caracteriza-se por possuir menor nível de regulação no processo de elaboração de normas e, consequentemente, maior discricionariedade por parte dos gestores em suas escolhas contábeis.

Williams (1999) argumentou que as empresas, em um ambiente sociopolítico e econômico voltado para o desenvolvimento de regulamentação, inclusive relacionada à contabilidade, têm um incentivo maior para divulgar informações, principalmente por temerem pressão adicional por intervenção regulatória, o que comprometeria seus interesses; por outro lado, aqueles sob um sistema despreocupado em definir regras podem enfrentar expectativas sociais mais baixas quanto à divulgação de informações voluntárias e, desse modo, são menos incentivadas a revelar detalhes desse tipo de divulgação.

Lattemann et al. (2009) ensinam que, nas sociedades baseadas em regras, os cidadãos tendem a confiar mais nas informações públicas, tais como a comunicação corporativa (por exemplo, relatórios anuais e/ou relatórios sociais corporativos), o que faz com que as empresas possam obter vantagens ao comunicar a sua responsabilidade social. Isso pode ser representado por um interesse maior por parte dos stakeholders em manter relação com as empresas. Corroborando esse pensamento, Oliveira, Machado e Beuren (2012, p. 3), destacaram que "há uma tendência mundial dos investidores procurarem empresas socialmente responsáveis, sustentáveis e rentáveis para aplicar seus recursos".

A discussão acima leva à primeira hipótese do estudo:

H1: As empresas de países de sistema jurídico codificado (Code Law System) divulgam mais informações socioambientais.

\subsubsection{Inclusão em índices de sustentabilidade}

Cogita-se com frequência se o fato de empresas pertencerem a determinado segmento social, como por exemplo estarem cotadas 
em bolsas de valores, faz com que o nível de divulgação de suas informações ambientais seja afetado.

Monteiro e Aibar-Guzmán (2010), ao testarem empiricamente diversas características relacionadas a atributos das empresas que foram selecionadas para a pesquisa, visando a verificar a influência sobre o nível de divulgação ambiental, constataram que o fato de elas estarem cotadas na bolsa de valores está positivamente relacionado à extensão da divulgação ambiental.

Isso se explica, principalmente, por existir uma série de exigências para que as companhias componham esses índices. É o caso dos índices de sustentabilidade, compostos por aquelas consideradas como mais ambientalmente corretas e que atendem aos requisitos estabelecidos para composição deles, o que leva a pensar que também se trata das que mais divulgam informações socioambientais. Esse mesmo argumento foi utilizado por Gubiani, Santos e Beuren (2012) para justificar a escolha das empresas listadas no ISE como amostra do seu estudo.

Corroborando essa ideia, Rover et al. (2012) afirmaram que os índices de sustentabilidade propõem a formação de uma carteira que reflete o desempenho das empresas reconhecidamente sustentáveis. Assim, por serem companhias consideradas com desempenho ambiental superior à média, assume-se que o fato de pertencerem a esses índices faz com que evidenciem mais informações ambientais.

Múrcia et al. (2008), buscando explicar o disclosure voluntário ambiental das empresas listadas na Bolsa de Valores de São Paulo e pertencentes aos setores de alto impacto ambiental, confirmaram a hipótese de que o fator "participação no ISE" é relevante em nível de significância de 5\%, ou seja, o fato de elas serem listadas no ISE faz com que divulguem mais informações ambientais.

Essas considerações levam à segunda hipótese do estudo:

H2: As empresas que participam de índice de sustentabilidade de bolsas de valores de seus países apresentam um nível maior de divulgação de informações socioambientais.

\subsubsection{Verificação de relatórios socioambientais}

A divulgação de informações ambientais, embora voluntária, pode ser verificada por auditores independentes com o intuito de 
oferecer credibilidade às partes interessadas (BRAGA; SANTOS; SILVA, 2015). O fato de as empresas utilizarem serviços de firmas de auditoria atuantes pode impactar o nível de divulgação de informações ambientais dos relatórios de sustentabilidade, já que, segundo Ahmad, Hassan e Mohammad (2003), as empresas de auditoria geralmente não se associam a clientes que evidenciam poucas informações ambientais, principalmente as Big Four (KPMG, PriceWaterhouseCoopers, Deloitte Touche Tohmatsu e ErnstEYoung).

$\mathrm{O}$ incentivo para que as companhias divulguem o máximo possível de informações advém do fato de que os auditores incorrem em custos ao assinarem contratos com novos clientes (WATTS; ZIMMERMAN, 1978) ou, em casos extremos, respondem por custos da não divulgação de determinada informação ou ainda custos de litígios que envolvem a adulteração das demonstrações contábeis evidenciadas (ROVER et al., 2012).

Silva et al. (2015) investigaram os fatores que influenciam as divulgações ambientais nos relatórios anuais das empresas listadas na BM\&FBOVESPA referentes a 2012 de 43 empresas que estão inseridas nos setores de alto impacto ambiental de acordo com a Lei 10.165/00. Eles encontraram como um dos resultados que as organizações privadas auditadas por uma das Big Four tendem a fazer mais divulgações ambientais nos seus relatórios anuais do que as não auditadas e do que as empresas públicas auditadas ou não por uma das Big Four.

Murcia et al. (2008) confirmaram que a variável empresas de auditoria é relevante para explicar o disclosure voluntário ambiental; ou seja, companhias auditadas por uma das Big Four evidenciam mais informações de caráter ambiental. Do mesmo modo, Rover et al. (2012) também observaram que, entre os fatores que determinam a divulgação voluntária ambiental pelas empresas brasileiras potencialmente poluidoras, o fato de a companhia ser auditada por uma das Big Four apresenta uma relação positiva em comparação às auditadas por outras.

A constatação do citado estudo corroborou o trabalho de Ahmad, Hassan e Mohammad (2003) que, ao examinarem o que motiva as empresas da Malásia a divulgarem informações ambientais, concluíram que o fato de serem auditadas pelas Big Four faz com que tenham maior nível de disclosure. 
Isso leva à terceira hipótese para este estudo:

H3: As empresas que submetem os relatórios de sustentabilidade à verificação externa evidenciam um nível maior de divulgação de informações socioambientais.

As três hipóteses delineadas anteriormente abrangem a ideia de que os três aspectos elencados associados aos três isomorfismos podem explicar o nível de divulgação de informações ambientais das empresas dos países do BRICS (Figura 1).

Figura 1: Associação das hipóteses aos isomorfismos

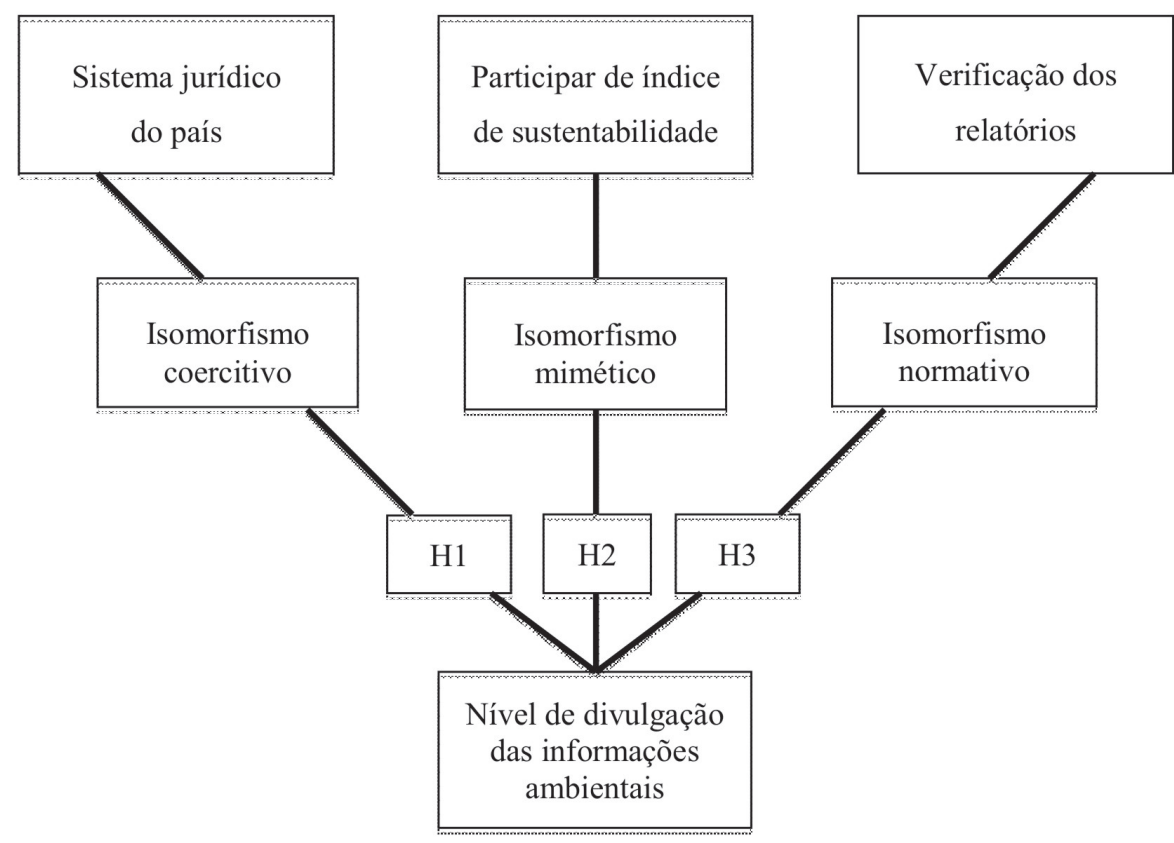

Fonte: Elaborada pelos autores.

\section{Metodologia}

Trata-se de estudo descritivo com abordagem quantitativa dos dados. Os relatórios anuais e de sustentabilidade foram colhidos a partir da Internet e dos sítios virtuais das empresas da amostra e 
analisados utilizando-se como parâmetro os indicadores de sustentabilidade da GRI.

Como técnica de coleta de dados foi utilizada a análise de conteúdo para se obter uma visão geral da divulgação de cada um dos indicadores de desempenho ambiental da GRI pelas empresas pesquisadas. As categorias de análise foram os indicadores de desempenho ambiental do relatório GRI, modelo G3.1. Embora a GRI tenha lançado o modelo G4, composto por 34 indicadores de desempenho ambiental, só foi exigido o atendimento a esse modelo a partir de janeiro de 2016. Devido a esse período de adequação concedido às empresas, grande parte dos relatórios de sustentabilidade até 2015 foi elaborada conforme o modelo G3.1, o que justifica a escolha desse modelo.

Os indicadores ambientais do modelo G3.1 da GRI, num total de 30, são distribuídos em dois grupos: essenciais (totalizando 17) e adicionais (totalizando 13). Para este estudo, foram considerados os 17 indicadores essenciais da categoria ambiental, conforme o Quadro 1.

Quadro 1: Categorias e indicadores essenciais de desempenho ambiental

\begin{tabular}{|c|c|}
\hline Categoria & Indicadores \\
\hline \multirow{2}{*}{ Materiais } & EN1 - Materiais usados, por peso ou volume. \\
\hline & $\begin{array}{l}\text { EN2 - Percentual dos materiais usados provenientes } \\
\text { de reciclagem. }\end{array}$ \\
\hline \multirow{2}{*}{ Energia } & $\begin{array}{l}\text { EN3 - Consumo de energia direta, discriminado por } \\
\text { fonte de energia primária. }\end{array}$ \\
\hline & $\begin{array}{l}\text { EN4 - Consumo de energia indireta, discriminado } \\
\text { por fonte primária. }\end{array}$ \\
\hline Água & EN8 - Total de retirada de água, por fonte. \\
\hline \multirow{2}{*}{ Biodiversidade } & $\begin{array}{l}\text { EN11 - Localização e tamanho da área possuída, } \\
\text { arrendada ou administrada dentro de áreas prote- } \\
\text { gidas, ou adjacentes a elas, e áreas de alto índice de } \\
\text { biodiversidade fora das áreas protegidas. }\end{array}$ \\
\hline & $\begin{array}{l}\text { EN12 - Descrição de impactos significativos na bio- } \\
\text { diversidade de atividades, produtos e serviços em } \\
\text { áreas protegidas e em áreas de alto índice de biodi- } \\
\text { versidade fora das áreas protegidas. }\end{array}$ \\
\hline
\end{tabular}




\begin{tabular}{|c|c|}
\hline Categoria & Indicadores \\
\hline \multirow{7}{*}{$\begin{array}{l}\text { Emissões, } \\
\text { efluentes e } \\
\text { resíduos }\end{array}$} & $\begin{array}{l}\text { EN16 - Total de emissões diretas de gases de efeito } \\
\text { estufa, por peso. }\end{array}$ \\
\hline & $\begin{array}{l}\text { EN17 - Emissões indiretas relevantes de gases de } \\
\text { efeito estufa, por peso. }\end{array}$ \\
\hline & $\begin{array}{l}\text { EN19 - Emissões de substâncias destruidoras da } \\
\text { camada de ozônio, por peso. }\end{array}$ \\
\hline & $\begin{array}{l}\text { EN20 - NOx, SOx e outras emissões atmosféricas } \\
\text { significativas, por tipo e peso. }\end{array}$ \\
\hline & $\begin{array}{l}\text { EN21 - Descarte total de água, por qualidade e } \\
\text { destinação. }\end{array}$ \\
\hline & $\begin{array}{l}\text { EN22 - Peso total de resíduos, por tipo e método de } \\
\text { disposição. }\end{array}$ \\
\hline & $\begin{array}{l}\text { EN23 - Número e volume total de derramamentos } \\
\text { significativos. }\end{array}$ \\
\hline \multirow{2}{*}{$\begin{array}{l}\text { Produtos e ser- } \\
\text { viços }\end{array}$} & $\begin{array}{l}\text { EN26 - Iniciativas para mitigar os impactos ambien- } \\
\text { tais de produtos e serviços e a extensão da redução } \\
\text { desses impactos. }\end{array}$ \\
\hline & $\begin{array}{l}\text { EN27 - Percentual de produtos e suas embalagens } \\
\text { recuperadas, em relação ao total de produtos vendi- } \\
\text { dos, por categoria de produto. }\end{array}$ \\
\hline Conformidade & $\begin{array}{l}\text { EN28 - Valor monetário de multas significativas e } \\
\text { número total de sanções não monetárias resultan- } \\
\text { tes da não conformidade com leis e regulamentos } \\
\text { ambientais. }\end{array}$ \\
\hline
\end{tabular}

Fonte: Adaptado das Diretrizes para Relatório de Sustentabilidade da GRI (2011).

Para viabilização das análises, cada indicador foi pontuado da seguinte forma:

0 - quando não houve divulgação de nenhum aspecto relacionado ao indicador;

1 - quando houve divulgação de algum aspecto relacionado ao indicador. 
Cada empresa pôde obter até 17 pontos de acordo com a quantidade de indicadores divulgados, e cada país pôde obter até o máximo da quantidade de empresas vezes 17 pontos. Assim, a pontuação de cada empresa recebeu um valor inteiro entre 0 e 17, conforme presença dos indicadores ambientais essenciais divulgados, e desse modo foi calculado o nível de divulgação a partir da pontuação.

Para cada empresa de cada país, foi utilizada uma planilha no software Excel preenchida com os dados coletados sobre a divulgação encontrada dos indicadores ambientais, conforme orientações da GRI e com informação sobre a divulgação ou não dos indicadores. Neste último caso levantou-se se a empresa elabora o relatório no modelo GRI ou não, o nível de aplicação do relatório $(\mathrm{A}, \mathrm{A}+\mathrm{B}, \mathrm{B}+$, C, C+) e se ela pertence ou não ao Índice de Sustentabilidade bem como o tipo de verificação usada para o relatório ambiental (Big Four, GRI - A+, B+, C+ - ou outra organização autorizada pela GRI). Depois realizou-se a consolidação por país.

Para comparar o nível de divulgação das empresas, foram realizados os testes $\mathrm{T}$ para a diferença de médias, e o de Mann-Whitney, para verificar se as diferenças observadas nos níveis de divulgação desses grupos são significantes.

A ANOVA foi utilizada para examinar os grupos de isomorfismos. Foi considerado como variável dependente o nível de divulgação, e como independentes, os isomorfismos (coercitivo, normativo e mimético). Ela serviu também para comparar o nível de divulgação dos países, os quais também foram independentes. Juntamente com a ANOVA, foi realizado o teste de Kruskal-Wallis, visto que há quebra do pressuposto de normalidade para algumas das variáveis testadas. Para complementar a análise foi utilizada a árvore de regressão a fim de verificar qual aspecto mais influencia o nível de divulgação.

A amostra compreende as empresas do setor de energia elétrica cotadas em bolsa que compõem e não compõem os índices de sustentabilidade dos países do BRICS (Tabela 1). 
Tabela 1: Amostra das empresas dos países do BRICS que divulgaram relatórios anuais e de sustentabilidade referentes ao exercício de 2014

\begin{tabular}{l|l|llll}
\hline País & $\begin{array}{l}\text { Empresas } \\
\text { de EE lista- } \\
\text { das na BV }\end{array}$ & $\begin{array}{l}\text { Empresas de } \\
\text { EE pertencen- } \\
\text { tes ao Índice } \\
\text { de Sustentabi- } \\
\text { lidade }\end{array}$ & $\begin{array}{l}\text { Adota } \\
\text { GRI }\end{array}$ & $\begin{array}{l}\text { Não } \\
\text { adota } \\
\text { GRI }\end{array}$ & $\begin{array}{l}\text { Verificada por } \\
\text { uma das Big } \\
\text { Four (empre- } \\
\text { sas de audi- } \\
\text { toria) }\end{array}$ \\
\hline Brasil & 30 & 9 & 23 & 7 & 17 \\
\hline Rússia & 10 & 0 & 5 & 5 & 4 \\
\hline Índia & 25 & 7 & 3 & 22 & 2 \\
\hline China & 23 & 3 & 3 & 20 & 9 \\
\hline África do Sul & 2 & 1 & 2 & 0 & 1 \\
\hline TOTAL & 90 & 20 & 36 & 54 & 33 \\
\hline
\end{tabular}

Fonte: Elaborada pelos autores.

Diante da metodologia exposta, procedeu-se à análise e à discussão dos dados obtidos, tendo em vista o alcance dos objetivos propostos.

\section{RESUlTAdos E DisCUSSÃo}

As Tabelas 2 e 3 apresentam, respectivamente, a quantidade de companhias por país que divulgaram cada um dos indicadores e as medidas descritivas para cada divulgação.

Tabela 2: Divulgação de informação ambiental por indicador

\begin{tabular}{l|c|c|c|c|c}
\hline Indicador & Brasil & Rússia & Índia & China & África do Sul \\
\hline EN1 & 14 & 2 & 4 & 4 & 2 \\
EN2 & 7 & 3 & 2 & 3 & 1 \\
EN3 & 22 & 8 & 11 & 12 & 1 \\
EN4 & 21 & 3 & 2 & 0 & 1 \\
EN8 & 26 & 6 & 4 & 2 & 2 \\
EN11 & 17 & 3 & 3 & 0 & 1 \\
EN12 & 17 & 4 & 3 & 3 & 2 \\
EN16 & 21 & 7 & 9 & 6 & 2 \\
EN17 & 15 & 1 & 1 & 0 & 0 \\
EN19 & 9 & 1 & 5 & 1 & 2 \\
EN20 & 10 & 5 & 7 & 6 & 1 \\
EN21 & 16 & 8 & 4 & 5 & 2 \\
EN22 & 28 & 8 & 6 & 5 & 2 \\
EN23 & 19 & 2 & 3 & 1 & 0 \\
EN26 & 24 & 6 & 8 & 2 & 2 \\
EN27 & 0 & 0 & 1 & 0 & 1 \\
EN28 & 25 & 6 & 4 & 51 & 24 \\
\hline TOTAL & $\mathbf{2 9 1}$ & $\mathbf{7 3}$ & 77 & & \\
\hline
\end{tabular}

Fonte: Elaborada pelos autores. 
Tabela 3: Medidas descritivas para a divulgação dos países

\begin{tabular}{|c|c|c|c|c|c|c|}
\hline País & Mínimo & Máximo & Média & Mediana & Desvio & $\begin{array}{l}\text { Coeficiente } \\
\text { de variação }\end{array}$ \\
\hline Brasil & 2,000 & 16,000 & 9,700 & 9,000 & 3,466 & 0,357 \\
\hline Rússia & 0,000 & 15,000 & 7,300 & 7,000 & 4,596 & 0,630 \\
\hline Índia & 0,000 & 16,000 & 3,080 & 1,000 & 4,881 & 1,585 \\
\hline China & 0,000 & 12,000 & 3,080 & 1,000 & 3,133 & 1,017 \\
\hline África do Sul & 10,000 & 14,000 & 12,000 & 12,000 & 2,828 & 0,236 \\
\hline
\end{tabular}

Fonte: Elaborada pelos autores.

A fim de comparar o perfil de divulgação dos países do BRICS, realizou-se, inicialmente, uma ANOVA para comparar as médias de indicadores evidenciados pelas empresas desses países, conjuntamente com um teste de Kruskal-Wallis, que atende ao mesmo objetivo, porém se baseando em estatísticas não paramétricas. Os resultados são apresentados na Tabela 4.

Tabela 4: Comparação da divulgação dos países

\begin{tabular}{l|l|l|l|l}
\hline \multicolumn{2}{c}{ ANOVA } & \multicolumn{3}{c}{ Kruskal-Wallis } \\
\cline { 2 - 5 } & Estatística F & Significância & Quiquadrado & Significância \\
\hline $\begin{array}{l}\text { Indicadores } \\
\text { divulgados }\end{array}$ & 16,492 & 0,000 & 40,318 & 0,000 \\
\hline
\end{tabular}

Fonte: Elaborada pelos autores.

Como a significância obtida para os dois testes foi muito próxima de zero, pode-se afirmar que há diferenças estatisticamente relevantessignificantes entre as divulgações dos cinco países analisados. Assim sendo, complementou-se a análise por meio de um teste post-hoc de Tukey, a fim de verificar quais são diferentes e quais se assemelham entre si (Tabela 5). 
Tabela 5: Teste post-hoc Tukey para a diferença entre os países

\begin{tabular}{l|l|l|l|l}
\hline & \multicolumn{1}{|l|}{ Brasil } & Rússia & Índia & \multicolumn{1}{c}{ China } \\
\hline Rússia & 0,465 & & & \\
Índia & 0,000 & 0,043 & & \\
China & 0,000 & 0,009 & 0,943 & \\
África do Sul & 0,931 & 0,545 & 0,024 & 0,010 \\
\hline
\end{tabular}

Fonte: Elaborada pelos autores.

Pelos resultados apresentados na Tabela 5, é possível inferir que o perfil de divulgação do Brasil, da Rússia e da África do Sul não diferem estatisticamente entre si (são semelhantes) e que esses três países apresentam diferenças significantes com Índia e China, os quais, segundo os resultados dos testes, assemelham-se.

Da Tabela 3, pode-se perceber que o Brasil apresenta melhor índice de divulgação médio de indicadores, com 9,7. Cabe ressaltar que a África do Sul, apesar de ter maior média de divulgação, conta apenas com duas empresas, o que contribui para uma média de divulgação mais elevada que a dos demais países. Vale observar ainda que o Brasil, além da África do Sul, é o único país do BRICS em que todas as empresas divulgaram algum indicador, conforme pode ser observado pelo valor mínimo de dois deles publicados. O Brasil é também aquele que, juntamente com a Índia, apresenta a empresa com maior número de indicadores divulgados (16). Com isso depreende-se que nenhuma empresa do BRICS divulgou todos aqueles essenciais para o componente ambiental, conforme sugerido pelo GRI, os quais totalizam 17 indicadores.

Uma das explicações para que Brasil e Rússia tenham apresentado maior evidenciação é o fato de ambos possuírem um sistema jurídico codificado. Isso porque, segundo Williams (1999), as empresas em um ambiente sociopolítico e econômico voltado para o desenvolvimento de regulamentação, inclusive relacionada à contabilidade, têm um incentivo maior para divulgar informações, principalmente por temerem pressão adicional por intervenção regulatória, o que comprometeria os interesses delas.

$\mathrm{O}$ autor destaca ainda que as empresas sob um sistema despreocupado em definir regras podem enfrentar expectativas sociais mais baixas quanto à evidenciação de informações voluntárias e, desse modo, são menos incentivadas a revelar detalhes desse 
tipo de divulgação. Pode ser esse o caso de Índia e China, cujos sistemas jurídicos são consuetudinário e misto, respectivamente.

A média baixa de empresas que evidenciam indicadores cuja divulgação é pressionada por lei pode estar relacionada ao baixo enforcement existente nos países do estudo, como diversos estudos afirmam acerca da efetividade no cumprimento das leis em países emergentes (BLACK; CARVALHO; GORGA, 2010; CHENNUPATI, POTLURI; MAGNALE, 2013; DHARMAPALA; KHANA, 2013; ESTRIN; PREVEZER, 2011; JIA et al., 2009). Outra explicação pode estar associada ao fato de a publicação de informações ambientais não ser obrigatória, o que proporciona às empresas escolherem o que querem divulgar, tendo em vista principalmente sua legitimação.

De acordo com Braendle (2014), nos países do BRICS a aderência às regulamentações legais não é prejudicada pela fragilidade do sistema de legislação para relações corporativas, mas sim pelo baixo nível de efetividade de aplicação das leis. Esses resultados, portanto, confirmam a primeira hipótese do estudo.

Para evidenciar o efeito do isomorfismo mimético sobre a divulgação dos indicadores ambientais essenciais, foi comparado, por meio do teste $\mathrm{T}$ e de Mann-Whitney, o nível de divulgação de empresas que fazem parte de índices de sustentabilidade ou não (Tabela 6).

Na Tabela 6, observa-se que o Brasil é o país com maior quantidade de empresas participantes de índice de sustentabilidade, ficando em termos percentuais em segundo lugar (perde apenas para a África do Sul, cuja amostra contém apenas duas empresas). A Rússia não possui um índice de sustentabilidade.

Tabela 6: Comparação da divulgação entre empresas que fazem parte de indices de sustentabilidade ou não

\begin{tabular}{|c|c|c|c|c|c|c|}
\hline $\begin{array}{l}\text { Tipo de } \\
\text { informa- } \\
\text { ção }\end{array}$ & $\begin{array}{l}\text { Faz parte de } \\
\text { Índice de } \\
\text { Sustentabilidade }\end{array}$ & Média & Mediana & $\begin{array}{l}\text { Desvio- } \\
\text { padrão }\end{array}$ & Teste $\mathrm{T}$ & $\begin{array}{l}\text { Teste de } \\
\text { Mann- } \\
\text { Whitney }\end{array}$ \\
\hline BRICS & $\begin{array}{l}\text { Não } \\
\text { Sim }\end{array}$ & $\begin{array}{l}4,53 \\
9,95 \\
\end{array}$ & $\begin{array}{l}3,00 \\
12,00 \\
\end{array}$ & $\begin{array}{l}4,399 \\
5,511 \\
\end{array}$ & 0,000 & 0,000 \\
\hline Brasil & $\begin{array}{l}\text { Não } \\
\text { Sim }\end{array}$ & $\begin{array}{l}8,57 \\
12,33 \\
\end{array}$ & $\begin{array}{l}8,00 \\
13,00 \\
\end{array}$ & $\begin{array}{l}3,091 \\
2,915 \\
\end{array}$ & 0,018 & 0,002 \\
\hline Índia & $\begin{array}{l}\text { Não } \\
\text { Sim }\end{array}$ & $\begin{array}{l}0,89 \\
8,71 \\
\end{array}$ & $\begin{array}{l}1,00 \\
8,00\end{array}$ & $\begin{array}{l}0,963 \\
6,422\end{array}$ & 0,026 & 0,002 \\
\hline China & $\begin{array}{l}\text { Não } \\
\text { Sim }\end{array}$ & $\begin{array}{l}1,90 \\
4,33 \\
\end{array}$ & $\begin{array}{l}1,00 \\
1,00\end{array}$ & $\begin{array}{l}0,963 \\
6,422 \\
\end{array}$ & 0,593 & 0,813 \\
\hline
\end{tabular}

Fonte: Elaborada pelos autores. 
Os resultados permitem inferir que tanto para o BRICS como um todo, considerando-se apenas os países que possuem índice de sustentabilidade, como para o Brasil e a Índia, as empresas que fazem parte de tal índice apresentam média superior àquelas que não fazem parte. Os testes T e de Mann-Whitney permitem afirmar ainda que a diferença observada no número de indicadores divulgados entre os dois grupos é estatisticamente significante, ou seja, há de fato uma divulgação maior por parte de empresas que fazem parte do índice de sustentabilidade de seus países.

Esse resultado confirma a hipótese 2 do estudo e corrobora a afirmação de Rover et al. (2012) sobre a evidenciação de informações socioambientais ser maior por empresas consideradas com desempenho ambiental superior à média e pertencentes a índices de sustentabilidade. Este estudo também confirma nas empresas do BRICS os resultados de Múrcia et al. (2008), que encontraram maior nível de divulgação ambiental em empresas de sua amostra que participavam em índices de sustentabilidade.

No caso da China, nota-se que a média de divulgação das empresas que não fazem parte de índice de sustentabilidade supera o que foi observado para aquelas que fazem parte. No entanto, os testes realizados não permitem afirmar que essa diferença observada é estatisticamente significante, e não é possível confirmar que as que não fazem parte de índice divulgam mais que aquelas que fazem.

Cabe salientar que esse tipo de comparação não foi possível para a Rússia, posto que ela não possui um índice de sustentabilidade, nem para a África do Sul, já que há apenas uma empresa de cada tipo entre as analisadas para esse país.

Para identificar uma possível influência de pressões normativas sobre a divulgação de informação ambiental das empresas do BRICS, foi realizado um teste T e de Mann-Whitney, buscando comparar o nível de divulgação das empresas conforme a instituição que realiza a verificação dos relatórios - uma das Big Four ou não e ainda se não é realizada verificação. A Tabela 7 apresenta o resultado consolidado para o BRICS e segregado por país. Vale ressaltar que das duas empresas da África do Sul, somente uma submete seu relatório a verificação, impossibilitando a análise desse aspecto. 
Tabela 7: Comparação do nível de divulgação conforme Relatório de Sustentabilidade verificado por Big Four ou não

\begin{tabular}{|c|c|c|c|c|c|c|c|}
\hline País & \multicolumn{2}{|c|}{$\begin{array}{l}\text { Auditada por } \\
\text { Big Four }\end{array}$} & Média & Mediana & $\begin{array}{l}\text { Desvio- } \\
\text { padrão }\end{array}$ & Teste $\mathrm{T}$ & $\begin{array}{l}\text { Teste de } \\
\text { Mann-Whitney }\end{array}$ \\
\hline BRICS & $\begin{array}{l}\text { Não } \\
\text { Sim }\end{array}$ & \begin{tabular}{|l|}
57 \\
33 \\
\end{tabular} & $\begin{array}{l}4,40 \\
8,03\end{array}$ & $\begin{array}{l}3,00 \\
9,00\end{array}$ & $\begin{array}{l}4,305 \\
5,747\end{array}$ & 0,003 & 0,012 \\
\hline Brasil & $\begin{array}{l}\text { Não } \\
\text { Sim }\end{array}$ & $\begin{array}{l}13 \\
17 \\
\end{array}$ & $\begin{array}{l}8,15 \\
10,88 \\
\end{array}$ & $\begin{array}{l}7,00 \\
11,00 \\
\end{array}$ & $\begin{array}{l}3,602 \\
2,934 \\
\end{array}$ & 0,030 & 0,020 \\
\hline Rússia & $\begin{array}{l}\text { Não } \\
\text { Sim }\end{array}$ & $\begin{array}{l}6 \\
4\end{array}$ & $\begin{array}{l}6,33 \\
8,75\end{array}$ & $\begin{array}{l}6,00 \\
10,00\end{array}$ & $\begin{array}{l}2,805 \\
6,752\end{array}$ & 0,538 & 0,454 \\
\hline Índia & $\begin{array}{l}\text { Não } \\
\text { Sim }\end{array}$ & $\begin{array}{l}23 \\
2\end{array}$ & $\begin{array}{l}2,00 \\
15,50\end{array}$ & $\begin{array}{l}1,00 \\
15,50\end{array}$ & $\begin{array}{l}0,707 \\
3,275\end{array}$ & 0,000 & 0,007 \\
\hline China & $\begin{array}{l}\text { Não } \\
\text { Sim }\end{array}$ & $\begin{array}{l}14 \\
9\end{array}$ & $\begin{array}{l}3,36 \\
0,44\end{array}$ & $\begin{array}{l}1,50 \\
0,00\end{array}$ & $\begin{array}{l}3,522 \\
1,014\end{array}$ & 0,010 & 0,001 \\
\hline
\end{tabular}

Fonte: Elaborada pelos autores.

Os resultados mostram que, para o BRICS como um todo, empresas cujo relatório de sustentabilidade foi verificado por Big Four têm maior nível de divulgação do que as demais. Apesar de ter apresentado média superior de divulgação para empresas cujo relatório foi auditadoverificado por Big Four, os testes realizados para a Rússia não permitem inferir que há diferenças estatisticamente significantes entre os dois grupos desse país.

Foi realizado novo teste $\mathrm{T}$ e de Mann-Whitney, dessa vez buscando comparar o nível de divulgação das empresas quanto à verificação externa ou não de seus relatórios por uma das Big Four, pela GRI ou por outra organização autorizada por esta (Tabela 8).

Tabela 8: Comparação do nível de divulgação das empresas segundo seus relatórios sejam verificados ou não

\begin{tabular}{|c|c|c|c|c|c|c|c|}
\hline \multicolumn{3}{|c|}{ Verificação externa } & Média & Mediana & $\begin{array}{l}\text { Desvio- } \\
\text {-padrão }\end{array}$ & $\begin{array}{l}\text { Teste } \\
\mathrm{T}\end{array}$ & $\begin{array}{l}\text { Mann- } \\
\text {-Whitney }\end{array}$ \\
\hline BRICS & $\begin{array}{l}\text { Não } \\
\text { Sim }\end{array}$ & $\begin{array}{l}50 \\
40\end{array}$ & $\begin{array}{l}3,86 \\
8,08\end{array}$ & $\begin{array}{l}2,00 \\
8,50\end{array}$ & $\begin{array}{l}4,071 \\
5,460\end{array}$ & ,000 & 001 \\
\hline
\end{tabular}

Fonte: Elaborada pelos autores.

Os resultados evidenciam que, para o BRICS como um todo, empresas cujos relatórios passam por verificação externa têm maior nível de divulgação do que as demais. Isso confirma a hipótese 3 e 
corrobora as conclusões de Ahmad, Hassan e Mohammad (2003), Murcia et al. (2008), Rover et al. (2012) e Silva et al. (2015) de que as companhias cujos relatórios são verificados por Big Four apresentam maior nível de divulgação.

A árvore de regressão mostrou o aspecto mais relevante para o nível de divulgação e as características das empresas com maior e menor níveis de evidenciação (Figura 2).

Figura 2: Árvore de regressão para a divulgação dos países do BRICS

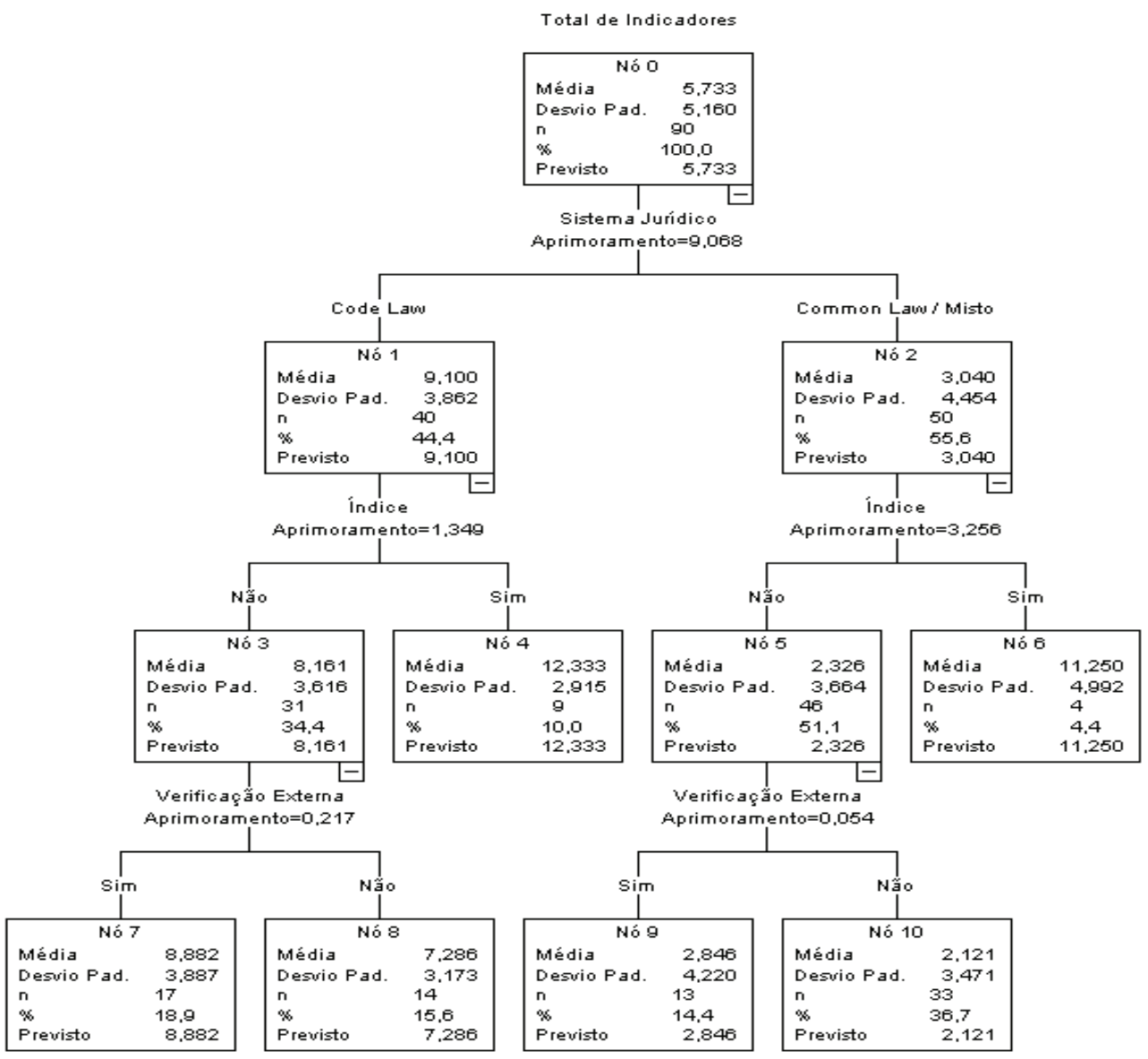


Importância da variável independente

\begin{tabular}{|l|l|l|}
\hline Variável independente & Importância & Importância normalizada \\
\hline Índice & 11,235 & $100,0 \%$ \\
\hline Sistema jurídico & 9,068 & $80,7 \%$ \\
\hline Verificação externa & 4,659 & $41,5 \%$ \\
\hline
\end{tabular}

Fonte: Elaborada pelos autores.

Ao se analisar a árvore de regressão da Figura 2, têm-se inicialmente todas as empresas do BRICS, cuja média de indicadores divulgados é de 5,733. Em seguida, há uma divisão entre as empresas dos países cujo sistema jurídico é Code Law (Brasil e Rússia), com média de divulgação de 9,100, e as empresas cujo sistema jurídico é Common Law (Índia, África do Sul) ou misto (China), com média de 3,040.

Nas empresas cujo sistema jurídico do país ao qual pertencem é o Code Law, aquelas que fizerem parte de índice de sustentabilidade de seu país (nesse caso as brasileiras, já que a Rússia não possui índice de sustentabilidade) têm média de divulgação de 12,333 indicadores; por sua vez, as que não fazem parte (incluindo as da Rússia) divulgam apenas 8,161 indicadores, em média. Por fim, dessas companhias que não fazem parte de índice de sustentabilidade, as que realizam verificação externa nos relatórios divulgam 8,882 indicadores em média, ao passo que as que não realizam divulgam em média 7,286 indicadores.

Nas empresas cujo sistema jurídico do país ao qual pertencem é Common Law ou misto, quando fazem parte de índice de sustentabilidade, divulgam em média 11,250 indicadores, e as que não fazem parte apresentam 2,326 indicadores. Dessas companhias que não integram índices de sustentabilidade de seus países, aquelas cujos relatórios foram verificados por uma das Big Four, pela GRI ou por outra organização autorizada por esta divulgam em média 2,846 indicadores; por sua vez, as que não são auditadas por empresas desse tipo têm média de divulgação de 2,121 indicadores.

Da análise da árvore, depreende-se que as empresas com melhor perfil de divulgação são brasileiras e russas, e, dentre elas, aquelas que fazem parte de índice de sustentabilidade. Já as que menos divulgam são aquelas cujo país ao qual pertencem é Common Law ou misto que não fazem parte desse tipo de índice. 
Os resultados apresentados responderam ao problema de pesquisa deste estudo, ao confirmarem a influência do ambiente institucional dos países aos quais as empresas pertencem no nível de divulgação de informações ambientais. A árvore de regressão permitiu ainda que fosse verificada a importância relativa de cada variável para obtenção do perfil de divulgação de indicadores das empresas. Por meio dessa análise, chegou-se à conclusão de que pertencer ao índice de sustentabilidade do país foi a variável que mais contribuiu para determinar o nível de divulgação, com 100,0\% de importância; a ela seguiu-se a variável sistema jurídico do país, com $80,7 \% \%$, e por último a verificação externa dos relatórios, com 49,9\%. Ou seja, houve empresas que não pertenciam a países com sistema jurídico Code Law nem seus relatórios de sustentabilidade foram verificados por uma Big Four, pela GRI ou por outra autorizada por esta e que tiveram elevados níveis de divulgação, por pertencerem a índices de sustentabilidade.

Ressalta-se que, do total de empresas que compuseram a amostra, 44,4\% fazem parte de países com sistema jurídico Code Law e $36,67 \%$ apresentam relatórios com verificação externa. Portanto, pode-se afirmar que a maior influência na divulgação foi o fato de as empresas pertencerem a índices de sustentabilidade de seus países, sobressaindo-se a pressão cultural como instrumento que mais influenciou o nível de divulgação dos indicadores ambientais.

Para melhor evidenciação sobre a confirmação ou não das hipóteses do estudo, elaborou-se o Quadro 2. 
Quadro 2: Evidenciação da confirmação ou não das hipóteses delineadas para o estudo

\begin{tabular}{|l|l|l|}
\hline \multicolumn{1}{|c|}{ HIPÓTESES } & \multicolumn{1}{c|}{ ACHADOS } & RESULTADO \\
\hline $\begin{array}{l}\text { H1: As empresas de países de } \\
\text { sistema jurídico codificado (Code } \\
\text { Law) são mais propensas a divul- } \\
\text { gar informações socioambientais. }\end{array}$ & $\begin{array}{l}\text { O Brasil apresentou o melhor } \\
\text { índice de divulgação médio de } \\
\text { indicadores, com 9,7. Em segun- } \\
\text { do lugar ficou a Rússia, com uma } \\
\text { média de 7,3 indicadores divul- } \\
\text { gados por empresa. }\end{array}$ & Confirmada \\
\hline $\begin{array}{l}\text { H2: As empresas que pertencem a } \\
\text { um índice de sustentabilidade de } \\
\text { bolsas de valores de seus países } \\
\text { apresentam um nível maior de di- } \\
\text { vulgação de informações socioam- } \\
\text { bientais. }\end{array}$ & $\begin{array}{l}\text { Nas empresas brasileiras e } \\
\text { sul-africanas, a média foi de 12,5 } \\
\text { para as que pertencem a índices } \\
\text { de sustentabilidade, e 8,2 para as } \\
\text { que não pertencem. }\end{array}$ & Confirmada \\
\hline $\begin{array}{l}\text { H3: As empresas que possuem } \\
\text { um relatório verificado pela GRI } \\
\text { ou empresas de auditoria atuan- } \\
\text { tes como as Big Four ou outra } \\
\text { autorizada pela GRI evidenciam } \\
\text { um nível maior de divulgação de } \\
\text { informações socioambientais. }\end{array}$ & $\begin{array}{l}\text { No BRICS como um todo, empre- } \\
\text { sas auditadas por Big Four têm } \\
\text { maior nível de divulgação do } \\
\text { que as demais. Também consta- } \\
\text { tou-se maior nível de divulgação } \\
\text { para as empresas que realizam } \\
\text { verificação externa de seus rela- } \\
\text { tórios. }\end{array}$ & Confirmada \\
\hline
\end{tabular}

Fonte: Elaborado pelos autores.

Conforme o resultado das análises realizadas, verificou-se a comprovação das hipóteses delineadas para o estudo. Entretanto, é importante destacar que a que se sobressaiu foi a de que empresas pertencentes a índices de sustentabilidade divulgam mais informações ambientais do que as que não pertencem a esses índices, confirmando a influência do Pilar Cultural da Teoria Institucional, representado pelo isomorfismo mimético na divulgação dessas informações.

Isso ressalta o papel relevante que as instituições como as bolsas de valores e seus índices de sustentabilidade exercem na divulgação de informações ambientais, tendo se sobressaído até mesmo à GRI e às práticas profissionais de auditoria. Tal fato pode ser explicado pelos altos custos envolvidos na contratação desses serviços e também pelo próprio sistema jurídico do país, o que pode ser justificado 
pela baixa efetividade no cumprimento das leis, também conhecida como enforcement.

\section{CoNCLUSÃo}

Observou-se a variação na divulgação dos indicadores, pois alguns foram muito divulgados pelas empresas de alguns países e ao mesmo tempo pouco divulgados por outras. Nesse contexto, Brasil e Rússia tiveram divulgações parecidas, destacando-se como os que mais divulgaram; Índia e China, por sua vez, destacaram-se como os que apresentaram os menores níveis de divulgação em relação à quantidade de empresas analisadas e à quantidade de indicadores divulgados por elas.

Constatou-se neste estudo a presença do isomorfismo mimético, conforme resultado encontrado de que as empresas que apresentaram os maiores níveis de divulgação foram as que pertencem a índices de sustentabilidade. Inferiu-se que elas podem estar imitando umas às outras por fazerem parte desses índices ou seguindo o regulamento, como no caso do Brasil e, portanto, sofrerem as mesmas expectativas de níveis elevados de divulgação, já que são consideradas mais ambientalmente corretas e por participarem de seleções anuais para composição das carteiras desses índices em que um dos critérios analisados é a divulgação ambiental.

Conforme levantamento da existência de leis e normas a pressionarem a divulgação dos indicadores ambientais analisados, constatou-se que em todos os países do BRICS quase a totalidade possuía lei ou norma. Entretanto, percebe-se que esse fato não influenciou a divulgação das empresas da Índia e da China, apesar de quase todos os indicadores serem pressionados por lei e norma; ao mesmo tempo, foram esses os países que obtiveram níveis de divulgação mais baixos. Desse modo, não houve influência do isomorfismo coercitivo nesses países cujos sistemas jurídicos são Common Law ou misto. Já com relação aos países de sistema jurídico codificado, percebeu-se a influência do isomorfismo coercitivo, considerando-se que Brasil e Rússia, que apresentaram os maiores níveis, são também os únicos que possuem sistema jurídico codificado. Isso confirma as expectativas sociais de que empresas sob um sistema preocupado em definir regras, como as empresas que pertencem a 
setores fortemente regulamentados, como é o caso das empresas de energia elétrica, divulgam mais informações ambientais.

Encontrou-se também a influência positiva do isomorfismo normativo, pois os níveis mais elevados de divulgação também foram das empresas que tiveram relatórios auditados por uma das Big Four, ou verificados pela GRI ou por outra organização autorizada por esta. Ademais, observou-se que as companhias que mais divulgaram também foram as que seguiram as diretrizes da GRI para elaboração de relatórios de sustentabilidade e que, além disso, tiveram os relatórios verificados. Desse modo, percebeu-se uma tendência maior ao seguimento das orientações da GRI, segundo as quais as empresas devem realizar auditoria em seus relatórios - ainda que isso não seja obrigatório - visando a alcançar maior credibilidade em suas informações.

Em geral se observou que a divulgação ambiental precisa ser melhorada, com vistas à construção de uma imagem positiva perante a comunidade e os demais interessados nesse tipo de informação.

Reconhecendo-se as limitações da pesquisa, cujo foco foram as empresas de energia elétrica dos países do BRICS, propõe-se a elaboração de outras no âmbito da divulgação ambiental que envolvam outros setores e também a comparação com países desenvolvidos, por exemplo, a fim de ampliar o conhecimento no assunto e apreender informações em contextos diversos. Sugerem-se também estudos que sejam amparados por outras teorias, com o intuito de atingir as peculiaridades dessas entidades. Propõe-se ainda o estudo com amostras menores para possibilitar análises mais profundas, inclusive qualitativas, por exemplo, por meio do exame detalhado do conteúdo das informações divulgadas, já que proporcionaria não somente constatar a existência da informação, mas sua essência.

\section{REFERÊNCIAS}

ABREU, M. C. S.; CUNHA, L. T.; BARLOW, C. Y. Institutional dynamics and organizations affecting the adoption of sustainable development in the United Kingdom and Brazil. Business Ethics: A European Review. v. 24, n. 1, p. 73-90, 2015.

AHMAD, Z.; HASSAN, S.; MOHAMMAD, J. Determinants of environmental reporting in Malaysia. International Journal of Business Studies, v. 11, n. 1, p. 69-90, 2003. 
BEUREN, I. M.; SANTOS, V.; GUBIANI, C. A. Informações ambientais evidenciadas no relatório da administração pelas empresas do setor elétrico listadas no ISE. BASE - Revista de Administração e Contabilidade da Unisinos, São Leopoldo, v. 10, n. 1, p. 55-68, 2013.

BEWLEY, K; LI, Y. Disclosure of environmental information by Canadian manufacturing companies: a voluntary disclosure perspective. Advances in Environmental Accounting \& Management, v. 1, n. 1, p. 201-226, 2000.

BLACK B. S.; DE CARVALHO, A. G.; GORGA, E. Corporate governance in Brazil. Emerging Markets Review, v. 11, n. 1, p. 21-38, 2010.

BOTINHA, R. A.; PONTES, G. A.; RECH, I. J. Relação entre gerenciamento de resultados e o sistema jurídico nas pesquisas publicadas nos periódicos nacionais e internacionais. Cadernos da FUCAMP, v. 12, n. 17, p. 98-113, 2013.

BRAENDLE, U. C. Recent developments in BRICS corporate governance with a focus on Russia - innovation or imitation? In: INTERNATIONAL CONFERENCE: "CORPORATE GOVERNANCE: A SEARCH FOR AVANCED STANDARDS IN THE WAKE OF CRISIS", Milan, 2014. Annals... Milan, 2014.

BRAGA, J. P.; OLIVEIRA, J. R. S.; SALOTTI, B. M. Determinantes do nível de divulgação ambiental nas demonstrações contábeis de empresas brasileiras. Rev. Cont. da UFBA, v. 3, n. 3, p. 81-95, 2009.

BRAGA, C.; SILVA, P. P.; SANTOS, A. Level of disclosure of environmental information in the electricity sector: an empirical study of Brazil and Iberian Peninsula. Global Journal of Management and Business Research, v. 15, n. 9, p. 39-53, 2015.

BROBERG, P.; TAGESSON, T.; COLLIN, S. O. What explains variation in voluntary disclosure? A study of the annual reports of corporations listed on the Stockholm Stock Exchange. Journal of Management and Governance, v. 14, n. 4, p. 351-377, 2010.

CARNEIRO, J. E.; DE LUCA, M. M. M.; OLIVEIRA, M. C. Análise das informações ambientais evidenciadas nas demonstrações financeiras das empresas petroquímicas brasileiras listadas na Bovespa. Contabilidade Vista \& Revista, v. 19, n. 3, p. 39-67, 2008.

CHENNUPATI, D. B.; POTLURI, R. M.; MAGNALE, V. S. India's right to information act, 2005: a catalyst for good governance. International J. of Law and Management, v. 55, n. 4, p. 295-303, 2013.

CUNHA, A. S.; SOARES, T. C.; LIMA, M. A. A institucionalização como forma de diferenciação frente ao isomorfismo organizacional. RAUnP, v. 3, n. 2, p. 8-14, 2011.

DE VILLIERS, C.; ALEXANDER, D. Isomorphism in social and environmental disclosures. In: PACIFIC INTERDISCIPLINARY RESEARCH IN ACCOUNTING CONFERENCE, 6., Sidney, 2010. Annals... Sidney, 2010. Disponível em: <http://apira2010.econ.usyd.edu.au/conference proceedings/APIRA-2010-196-deVilliers-Isomorphism-in-social-and-environmental-disclosures. pdf $>$. Acesso em: 14 fev. 2015.

DHARMAPALA, D.; KHANNA, V. Corporate governance, enforcement and firm value: evidence from India. The Journal of Law, Economics, and Organization, v. 29, n. 5, p. 1056-1084, 2013. 
DIAS FILHO, J. M.; MOURA, F. V. Evidenciações de informações sociais em seis bancos brasileiros - uma análise à luz da teoria institucional. Rev. Univ. Contábil, v. 9, n. 3, p. 06-21, 2013.

DIMAGGIO, P. J.; POWELL, W. W. The iron cage revisited: institutional isomorphism and collective rationality on organizational fields. American Sociological Review, v. 48, n.2, p. 147-160, 1983.

ESTRIN, S.; PREVEZER, M. The role of informal institutions in Corporate Governance: Brazil, Russia, India, and China compared. Asia Pacific J. of Management, v. 28, n. 1, p. 41-67, 2011.

GOMES, S. F. Auditoria aos relatórios de sustentabilidade das empresas portuguesas - uma visão sobre o estado da arte e a percepção dos revisores oficiais de contas. Xxx93 f. Dissertação (Mestrado em Controlo de GestãoXXXXXX) - Escola Superior de Tecnologia e Gestão, Instituto Publicitário de Leiria, Leiria, 2012.

GLOBAL REPORTING INITIATIVE. Diretrizes para Relatório de Sustentabilidade. 2011. Disponível em: <http: \\www.globalreporting.org/languages/Portuguesebrazil>. Acesso em: 15 jul. 2015.

GRECCO, M. C. P.; MILANI FILHO, M. A. F.; SEGURA, L. C.; SANCHEZ, I. M. G.; DOMINGUEZ, L. R. The voluntary disclosure of sustainable information: a comparative analysis of spanish and brazilian companies. Revista de Contabilidade e Organizações, v. 7, n. 17, p. 46-55, 2013.

GUBIANI, C. A.; SANTOS, V.; BEUREN, I. M. Disclosure ambiental das empresas de energia elétrica listadas no índice de sustentabilidade empresarial (ISE). Sociedade, Contabilidade e Gestão, v. 7, n. 2, p. 7-23, 2012.

HOSSAIN, M.; HAMMAMI, H. Voluntary disclosure in the annual reports of an emerging country: the case of Qatar. Advances in Accounting, v. 25, n. 2, p. 255-265, 2009.

JENSEN, J. C.; BERG, N. Determinants of traditional sustainability reporting versus integrated reporting. An institutionalist approach. Business Strategy and the Environment, v. 21, p. 299-316, 2012.

JIA, C.; DING, S.; LI, Y.; WU, Z. Fraud, enforcement action, and the role of corporate governance: evidence from China. Journal of Business Ethics, v. 90, n. 4, p. 561-576, 2009.

LATTEMANN, C.; FETSCHERIN, M.; ALON, I.; LI, S.; SCHNEIDER, A. M. CSR communication intensity in chinese and indian multinational companies. Corporate Governance: An International Review, v. 17, n. 4, p. 426-442, 2009.

LIU, X.; ANBUMOZHI, V. Determinant factors of corporate environmental information disclosure: an empirical study of chinese listed companies. Journal of Cleaner Production, v. 17 , n. 6, p. 593-600, 2009.

LUZ, A. R.; ROSSONI, L. Pressões ambientais, esquemas interpretativos e complexidade de departamentos contábil-financeiros. Rev. de Adm. da UNIMEP, v. 10, n. 2, p. 54-80, 2012.

MEYER, J. W.; ROWAN, B. Institutionalized organizations: formal structure as myth and ceremony. American Journal of Sociology, v. 83, n. 2, p. 340-363, 1977. 
MIKHAILOVA, I. Indicadores e políticas ambientais em países do BRICS: uma análise comparativa. In: ENCONTRO DA SOCIEDADE BRASILEIRA DE ECONOMIA ECOLÓGICA, 9., 2011, Brasília. Anais... Brasília, 2011.

MONTEIRO, S. M. S.; AIBAR-GUZMÁN, B. Determinants of environmental disclosure in the annual reports of large companies operating in Portugal. Corporate Social Responsibility and Environmental Management, v. 17, n. 4, p. 185-204, 2010.

MORISUE, H. M. M.; RIBEIRO, M. S.; PENTEADO, I. A. M. The evolution of sustainability reports of Brazilian companies of the electricity sector. Revista Contabilidade Vista \& Revista, v. 23, n. 1, p. 163-194, 2012.

MOSEÑE, J. A.; BURRITT, R. L.; SANAGUSTÍN, M. V.; MONEVA, J. M.; TINGEY-HOLYOAK, J. Environmental reporting in the spanish wind energy sector: an institutional view. Journal of Cleaner Production, v. 40, p. 199-211, 2013.

MURCIA, F. D.; ROVER, S.; LIMA, I.; FÁVERO, L. P. L.; LIMA, G. A. S. F. 'Disclosure verde' nas demonstrações contábeis: características da informação ambiental e possíveis explicações para a divulgação voluntária. Revista UnB Contábil, v. 11, n. 1-2, p. 260-278, 2008.

NORTH, D. C. Institutions. The Journal of Economic Perspectives, v. 5, n. 1, p. 97-112, 1991.

OLIVEIRA, M. C.; ARAÚJO JÚNIOR, J. F.; OLIVEIRA, O. V.; PONTE, V. M. R. Disclosure social de empresas brasileiras e britânicas à luz da Teoria Institucional. ASAA-Advances in Scientific and Applied Accounting, v. 5, n. 1, p. 2-26, 2012.

OLIVEIRA, A. F.; MACHADO, D. G.; BEUREN, I. M. Evidenciação ambiental de empresas de setores potencialmente poluidores listadas no índice de sustentabilidade empresarial (ISE). Revista de Gestão Social e Ambiental - RGSA, v. 6, n. 1, p. 20-37, 2012.

OLIVEIRA, M. C.; PONTE JUNIOR, J. E.; OLIVEIRA, O. V. Corporate social reporting practices of french and brazilian companies: a comparison based on institutional theory. Revista de Contabilidade e Organizações, v. 7, n. 18, p. 60-73, 2013.

RAMANUJAM, N.; VERNA, M.; BETTS, J.; CHARAMBA, K.; MOORE, M. Rule of law and economic development. Montreal: McGill University, 2012. Disponível em: <https://www. mcgill.ca/roled/files/roled/mcgill_roled_report_2012.pdf>. Acesso em: 12 jan. 2015.

RAUTENBACH, C.. South African common and customary law of intestate succession: a question of harmonization, integration or abolition. Eletronic J. of Comparative Law, v. 3, n. 1, p. $119,2008$.

RODRIGUES, L. F.; SALLABERRY, J. D. Análise do disclosure dos gastos ambientais em empresas do setor elétrico que compõem a carteira do índice de sustentabilidade empresarial (ISE) em 2011. Observatorio de la Economía Latinoamericana, v. 173, p. 1-11, 2012.

ROLDAN, V. P. S.; CABRAL, A. C. A.; PESSOA, M. N. M.; SANTOS, S. M.; ALVES, J. F. V. Gestão ambiental nas empresas de capital aberto do segmento novo mercado: discutindo a homogeneidade e heterogeneidade de práticas à luz da teoria institucional. Revista Eletrônica de Ciência Administrativa - RECADM, v. 11, n. 2, p. 193-216, 2012. 
ROVER, S.; TOMAZZIA, E. C.; MURCIA, F. D.; BORBA, J. A. Explicações para a divulgação voluntária ambiental no Brasil utilizando a análise de regressão em painel. Revista de Administração, v. 47, n. 2, p. 217-230, 2012.

SILVA, M. N.; LIMA, J. A. S. O.; FREITAS, M. A. L.; SILVA FILHO, L. L.; LAGIOIA, U. C, T. Determinantes do disclosure ambiental nos relatórios de empresas listadas na BM\&FBOVESPA. Revista Ambiente Contábil, v. 7, n. 2, p. 1-15, 2015.

SILVEIRA, M. L. G.; PFITSCHER, E. D. Responsabilidade socioambiental: estudo comparativo entre empresas de energia elétrica da região sul do Brasil. Perspectivas em Gestão \& Conhecimento, v. 3, n. 2, p. 177-195, 2013.

SEHNEM, S.; SANTOS JUNIOR, S.; DIAS, T. Sustentabilidade: uma análise dos artigos publicados nos eventos ANPAD. In: SIMPÓSIO INTERNACIONAL DE GESTÃO DE PROJETOS, 2., 2013, São Paulo. Anais... São Paulo, 2013.

SOUZA, M. A.; RÁSIA, K. A.; JACQUES, F. V. S. Evidenciação de informações ambientais pelas empresas integrantes do Índice de Sustentabilidade Empresarial - ISE. Revista Contabilidade e Controladoria - RC\&C, v. 2, n. 1, p. 51-76, 2010.

WATTS, R.; ZIMMERMAN, J. Towards a positive theory of the determination of accounting standards. Accounting Review, v. 53, n. 1, p.112-134, 1978.

WILLIAMS, S. M. Voluntary environmental and social accounting disclosure practices in the Asia-Pacific region: an international empirical test of political economy theory. The International Journal of Accounting, v. 34, n. 2, p. 209-238, 1999.

ZENG, S. X.; XU, X. D.; YIN, H. T.; TAM, C. M. Factors that drive chinese listed companies in voluntary disclosure of environmental information. J. Bus. Ethics, v. 109, n.3, p. 309-321, 2012.

ZIEGLER, A.; SCHRÖDER, M. What determines the inclusion in a sustainability stock index? A panel data analysis for European firms. Ecological Economics, v. 69, p. 848-856, 2010.

Recebido em: 30-03-2017

Aprovado em: 26-04-2017

Avaliado pelo sistema double blind review.

Editor: Elmo Tambosi Filho

Disponível em http://mjs.metodista.br/index.php/roc 